\title{
Theory of Inpatient Circadian Care (TICC): A Proposal for a Middle- Range Theory
}

\author{
Andrés Camargo-Sanchez ${ }^{*},{ }^{1}$, Carmen L. Niño ${ }^{1}$, Leonardo Sánchez ${ }^{1}$, Sonia Echeverri ${ }^{2}$, \\ Diana P. Gutiérrez ${ }^{3}$, Andrés F. Duque ${ }^{4}$, Oscar Pianeta ${ }^{5}$, Jenny A. Jaramillo-Gómez ${ }^{6}$, \\ Martin A. Pilonieta ${ }^{7}$, Nhora Cataño ${ }^{8}$, Humberto Arboleda ${ }^{9}$, Patricia V. Agostino ${ }^{10}$, \\ Claudia P. Alvarez-Baron ${ }^{11}$ and Rafael Vargas ${ }^{12}$
}

\author{
${ }^{I}$ Nursing School at the Universidad de Ciencias Aplicadas y Ambientales (U.D.C.A), Bogotá, Colombia \\ ${ }^{2}$ Nursing Department at Fundación Santa Fe de Bogotá University Hospital, Bogotá, Colombia \\ ${ }^{3}$ Division of Internal Medicine at Fundación Santa Fe de Bogotá University Hospital, Bogotá, Colombia \\ ${ }^{4}$ Surgical Department at Marly Clinic, Bogotá, Colombia \\ ${ }^{5}$ School of Medicine at the Universidad de Ciencias Aplicadas y Ambientales (U.D.C.A), Bogotá, Colombia \\ ${ }^{6}$ Cell Death Group, School of Medicine and Institute of Genetics at the Universidad Nacional de Colombia, Bogotá, \\ Colombia \\ ${ }^{7}$ School of Medicine at the Universidad Nacional de Colombia, Bogotá, Colombia \\ ${ }^{8}$ School of Nursing at the Universidad Nacional de Colombia, Bogotá, Colombia \\ ${ }^{9}$ Neurosciences Research Group, School of Medicine and Institute of Genetics at the Universidad Nacional de \\ Colombia, Bogotá, Colombia \\ ${ }^{10}$ Laboratorio de Cronobiología, Departamento de Ciencia y Tecnología, Universidad Nacional de Quilmes/CONICET, \\ Buenos Aires, Argentina \\ ${ }^{11}$ Department of Neuroscience, University of Wisconsin - Madison, Wisconsin, USA \\ ${ }^{12}$ School of Medicine at the Pontificia Universidad Javeriana, Bogotá, Colombia
}

\begin{abstract}
The circadian system controls the daily rhythms of a variety of physiological processes. Most organisms show physiological, metabolic and behavioral rhythms that are coupled to environmental signals. In humans, the main synchronizer is the light/dark cycle, although non-photic cues such as food availability, noise, and work schedules are also involved. In a continuously operating hospital, the lack of rhythmicity in these elements can alter the patient's biological rhythms and resilience. This paper presents a Theory of Inpatient Circadian Care (TICC) grounded in circadian principles. We conducted a literature search on biological rhythms, chronobiology, nursing care, and middle-range theories in the databases PubMed, SciELO Public Health, and Google Scholar. The search was performed considering a period of 6 decades from 1950 to 2013. Information was analyzed to look for links between chronobiology concepts and characteristics of inpatient care. TICC aims to integrate multidisciplinary knowledge of biomedical sciences and apply it to clinical practice in a formal way. The conceptual points of this theory are supported by abundant literature related to disease and altered biological rhythms. Our theory will be able to enrich current and future professional practice.
\end{abstract}

Keywords: Biological rhythms, chronobiology, circadian rhythms, hospital, middle-range theory, nursing.

\section{INTRODUCTION}

Inpatient care represents a challenge for health professionals because the requirements for each patient are diverse. Timing is a key element in patient care at hospitals

*Address correspondence to this author at the Universidad de Ciencias Aplicadas y Ambientales (U.D.C.A) at the School of Nursing, Bogotá, Colombia; Tel: +57 1 6684700; Fax: +57 16760096 ;

E-mail: andcamargo@udca.edu.co because almost all follow a schedule of interventions such as medication management, food management, laboratory sampling, testing, and visits. This alters the patient's own routine, which is already disturbed by the changes brought about by the disease, sleep disturbances and family dependency. Displacing the patient's lifestyle and family or work environment with the hospital environment that disengages their vital functions and daily activities from environmental factors can generate great stress. The environmental cues given by the social environment are changed by the regular hospital characteristics of noise peaks 
and constant light. Changes in routines and rhythms can alter the patient's recovery process and ability to adapt.

Understanding the presence of biological rhythms in healthy subjects and patients in relationship with their external environment, can contribute and strengthen the scientific rationale for nursing practice. Although there is abundant literature related to the topic of biological rhythms and their role in the homeostasis of the individual and disease, so far there is no middle-range theory that integrates existing knowledge of biological rhythms and patient care. The purpose of this paper is to propose a middle-range theory for inpatient circadian care.

\section{OVERVIEW OF THE THEORY OF INPATIENT CIRCADIAN CARE (TICC)}

Time is a phenomenon that affects the biological activities of organisms. Time-bound activities are present at all levels of biological organization from the cellular to the systemic level and are known as biological rhythms. Biological rhythms are known to all physiological phenomena that occur in a cyclical manner in living organisms. The importance of biological rhythms in living organisms stimulated the development of chronobiology, a line of physiology that was born with the congress on biological rhythms in Cold Spring Harbor (1960) directed by Prof. Dr. Franz Halberg [1]. Chronobiology studies the temporal organization of biological processes at the molecular, cellular, tissue, systemic and the individual levels, and the interactions between this organization and their environment, in order to establish a correlation between environmental events and the organization of biological functions.

Biological rhythms are mechanisms that prepare the body for predictable changes in the environment. One predictable event that occurs repeatedly over time at a constant interval is the day-night cycle [2, 3]. Biological rhythms are classified into three groups according to the 24-hour day: Ultradian rhythms are rhythms shorter than 24 hours; Infradian rhythms are rhythms lasting longer than 24 hour (weeks, months, or seasons); and Circadian rhythms have a period of about one day (the term circadian rhythm was coined by Franz Halderg from the Latin circa, "around" and dian "day", which literally means "about a day") [4]. Circadian rhythms are the most often studied rhythms due to their clinical implications and physiology [5-7].

Most physiological and behavioral functions in humans change over day and night. These changes allow organisms to anticipate and adapt to changes in the environment of light and dark which are linked to the rotation of the earth in a precise and controlled way [8-10]. This rhythmicity is generated by specific structures called endogenous biological clocks that are genetically encoded to generate internal organic fluctuations that respond to presence or absence of external signals. These fluctuations allow the development of adaptive processes by the individual towards environmental changes [11]. These changes provide the individual internal temporal order essential for the survival of the species. The main function of this internal order is to optimize metabolism and ensure the proper use of energy to sustain vital body processes, which requires a command from the central nervous system [6].

In mammals, the temporal control is performed from the suprachiasmatic nucleus (SCN), located in the hypothalamus. The SCN acts as a pacemaker through the expression of at least a dozen genes called clock genes. However, new evidence suggests that peripheral clocks exist in tissues of some organs to modulate many aspects of physiology and behavior, allowing for temporal homeostasis $[12,13]$.

\section{ZEITGEBERS OR "TIME-GIVERS"}

Addition to the internal factors, there are external factors that synchronize the internal clock to changes in the environment (the external synchronizers are called Zeitgebers or "time-givers"). The strongest synchronizer is the cycle of light/dark, which adjusts the timing of the circadian clock to a 24-hour interval. In addition to the light/dark cycle, various other factors such as food habits, social and working hours, and the administration of drugs for medical purposes may also affect biological rhythms in humans [5, 6, 14]. The light/dark cycle determines the sleep/wake cycle, one of the vital biological rhythms that is fundamental for life, body homeostasis, and recovery of body daily wear. This cycle is determined by endogenous factors, but also by external cues such as light and noise levels and working hours. Sleep/wake patterns can be unique to each individual and their alteration can cause health problems.

Illness and hospitalization processes constitute an important risk factor for disruption of the rest/activity and sleep/wake rhythms, which are also modified by other factors including age, anxiety, depression, pain, medication management, and hospital environment. Factors such as light and noise, typical of the hospital environment, can alter the beginning of the sleep phase $[15,16]$.

The TICC proposed theory has one key concept: adaptation. This concept is fundamental in the model of Roy, one of the theoretical models that support current nursing practice worldwide [17]. Several middle-range theories derived from the Roy adaptation model apply to all nursing practice and propose that the objective of patient care is to restore balance and conserve energy homeostasis [17]. Hospitalization processes cause a disturbance in life, requiring a period of compensation followed by adaptation, which can be positive or negative, and complete or incomplete [18]. These changes require the organism to implement strategies to effectively ensure its survival against challenges in everyday situations and critical periods of changes in the environment. Adaptation, homeostasis and survival are the goal of nursing care $[19,20]$.

Currently there is enough scientific evidence showing that rhythmicity and adaptability are key elements in the phenomenon of biological rhythms. Evidence also shows how these elements can determine health or disease. However, there is widespread lack of understanding among health professionals about this evidence and the implications of clinical interventions, care, and environmental factors, such as lighting, noise and sleep disturbances in hospitalized patients [21]. 


\section{THEORY DEVELOPMENT PROCESS}

The method employed in order to develop the middlerange theory about the "Inpatient Circadian Care (TICC)" was the same one employed for the development of the middle-range theory in aviation nursing: "Flight Nursing Expertise: towards a middle-range theory" [22].

Initially, key concepts were stated by the authors based on their previous knowledge and professional experience. The following key concepts were established: chronobiology, biological rhythms, circadian rhythms, hospital, and adaptation. These concepts guided an exhaustive literature review using databases such as PubMed, SciELO Public Health, and internet Google Scholar. The data search was done using the key terms: biological rhythms, chronobiology, circadian rhythms, nurse care, middle-range theories, and adaptation. The search was performed taking into account a period of 6 decades from 1950 to 2013. Finally, an analysis of the information and a discussion were done, supported by all the information that was found and the decades of experience in basic and clinic research for each author in the disciplines of nursing, medicine, chronobiology, neuroscience and genetics. In order to strengthen the conceptual frame of this theory, we integrated theoretical elements with clinical practice. Connections between concepts of chronobiology and the characteristics of the care for the hospitalized patient, focusing on the nursing care were examined. In order to build this new theory, inductive and deductive reasoning processes, supported in empiric evidence and experience, were used.

\section{OPERATIONAL DEFINITION OF CONCEPTS}

The middle-range "Inpatient Circadian Care" (TICC) has three basic building blocks:

1) The patient or circadian subject (time subject)

2) The synchronization process of a patient's biological rhythms

3) Hospital staff, synchronizers of a patient's biological rhythms and time-giver (Zeitgebers).

The following concepts arise from this theory: the circadian subject "I clock"; the "synchronization" process of biological rhythms of an individual, and the temporal environment or time giving environment represented in this model by the hospital staff "clockmaker" (Fig. 1).

Concept definitions:

\section{Circadian Human Being "I Clock"}

In the circadian human being, these rhythms are present throughout life. During prenatal life, the maternal circadian information adjusts the fetal internal clock, thus emmiting signals for labor initiation and birth. Later, in the neonatal stage, circadian cycles will depend on the light/darkness periods [23-30]. During the first years of life, the challenge for every individual is to adapt to a sleep/wake cycle appropriate to the surroundings. This sleep/wake cycle will adjust itself progressively, and it will be mediated by genetic and cultural factors that modulate the sleep habit throughout life [31]. The development of a sleep pattern coincides with the development of the central nervous system: "infant sleep can be considered as a window to observe the developing brain" [32]. It has been proposed that alterations in normal sleep development could expose problems in the development of the central nervous system and therefore, imply risks to a person's adaptation to the environment [32].

It is important to note that not all individuals are equal from the point of view of time. Different circadian phenotypes are called chronotypes. A chronotype is defined as the personal preference regarding the wake (activity) and sleep (rest) schedule. Three basic chronotypes have been described: morning (early bird), evening (night owls), and intermediates $[33,34]$.

Usually childhood, there is usually a preference for being an early riser. Due to hormonal changes, this preference may change during adolescence, between ages 12 to 16 , due in large part to hormonal influences. The individual becomes more of a night owl and increases the number of sleep hours at night, phase delaying such that they prefer to awaken in the late morning, closer to noon. This situation continues until about age 20 [35-37]. In adults, the sleep period is gradually reduced and tends to be common for the elderly to prefer a more phase advanced chronotype, with early bed times and early awakenings before dawn [38].

Extreme morning and evening chronotypes can also be considered. These features are mediated by a combination of genetic, demographic (age and gender), individual (personality, lifestyle, working conditions), and environmental factors such as geographic latitude [34, 35, $39,40]$.

Circadian rhythms not only modulate normal biochemical, physiological and behavioral variables on a daily basis, but also determine prognosis and response to treatment at the onset of disease. Many diseases also exhibit temporal structure: signs and symptoms vary during the day in conditions such as asthma, peptic ulcer, gastroesophageal reflux disease, hemorrhagic and ischemic stroke, epilepsy, myocardial infarction, hypertension, ventricular arrhythmias, cancer, depression, anxiety, bipolar disorder, and Alzheimer's disease. A common outcome for many of these diseases is death, and even this outcome may have a particular time of presentation [41-51].

\section{“Synchronization" Process}

Under disease conditions the circadian human being loses synchronization between the oscillations of the biological clock and the rest of the body, resulting in internal clock desynchronization with periods different from the 24-hour cycle (early or late phase). This can develop in patients with chronic diseases such as diabetes, hypertension, or cancer $[52,53]$. It may also be present in depressive states and other psychiatric disorders [54]. Given the high incidence and susceptibility of people to suffer from internal desynchronization, research and clinical observations suggest that individual genetic factors play a determinant role in both acute and chronic medical conditions $[55,56]$. Desynchronization of circadian rhythms (eg, sleep/wake cycle) is promptly manifested as sleep disturbance, persistent 


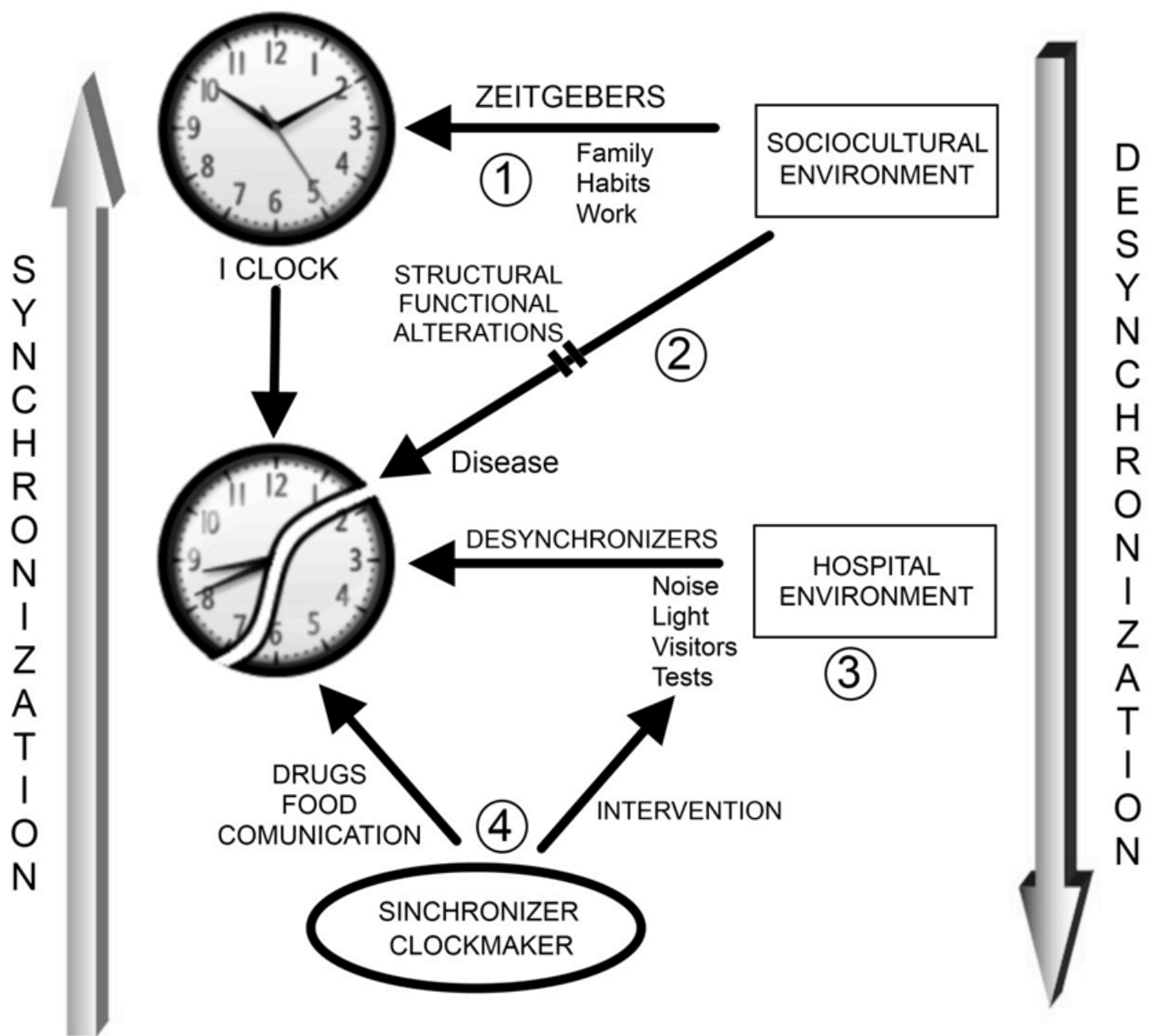

Fig. (1). Inpatient Circadian Care (TICC). Biological rhythms are regulated by the environment due to the presence of timers or Zeitgebers (1). Disease is characterized by structural and functional changes that can be caused by alterations in biologic rhythms and/or interfere with the internal rhythms of the individual (2). Hospitalization represents a new environment for the patient, with new ambient timers that can complicate the recovery of the patient (3). The role of nursing is to intervene with the factors, both external and individual, that contributes to the desynchronization of the internal rhythms to favor patient's recovery.

fatigue, hypnotic drug dependence, and impaired mood, including depression [57].

\section{Temporal Environment as a Synchronizer}

The spatial and temporal environments intervene in each of the concepts of ill person, nursing, and health in a complex person-environment interaction [58]. The circadian human being is subjugated to continuous adaptation through external time signals (Zeitgebers), with light being the most powerful, followed by feeding time, daily activity and resting, social interaction, and exercising. All these factors allow the individual to keep adapted and guided to the temporal environment in his daily activities [59-61]. Nevertheless, an asynchrony can present between the internal and external clocks, and the illumination/darkness cycle, caused by multiple factors: rapid travels through hour time zones, nocturnal working time, and exposition to excessive bright light at night. All of these factors generate desynchronization with the external time-givers [60, 62].

This state is called chronodisruption that is defined as a significant disturbance of the temporal internal order of the physiological, biochemical and behavioral circadian rhythms. Chronodisruption is associated with a higher incidence of metabolic syndrome, cardiovascular diseases, cognitive and affective disorders, sleep disorders, some types of cancer, premature aging, and accidents [63, 64]. Chronodisruption can be potentiated by the hospital as a new environment for the patient, a place where ambient clues appear different from clues generally found in daily activities: illumination, noise, infrastructure, temperature, workers, ventilation, security, visiting time, number of patients in each room, clinical assessment, invasive procedures, laboratory tests, and medications intake. All these elements together can alter the circadian synchronization of a patient physiologically, psychologically, and socially.

\section{"Clockmaker" and Circadian Rhythms in Hospitalized Patients}

The aim of hospital staff interventions is to allow hospitalized patients to conserve or restore in concordance with their internal clock and their environment. This can be accomplished using the following eight principles: 


\section{Control of Suitable Light/Dark Cycles}

Constant exposure to bright light, both during day and night, has negative effects on circadian rhythms [65], creating an inadequate environment to sleep [66]. It is important for nurses to take into account that proper exposure to light is essential for therapeutic stimulation, in order to help to maintain patient's circadian rhythms. In this sense, natural light/dark cycles can be simulated in hospitals, leading to a better distribution of the periods of activity/rest. Parameters such as light intensity, frequency and duration of light exposure, and spatial distribution, are already established [67]. For example, the Illuminating Engineer Society recommends daytime light levels of 30 lumens/ft for hospital rooms $[68,69]$.

\section{Noise Level Regulation}

Noise is a major source of environmental pollution and has a harmful effect on health and wellbeing. Sound levels higher than 40-45 decibels (dB) interfere with communication, disrupt sleep, and can lead to increased stress in patients. Recommended sound levels in hospital rooms are $35 \mathrm{~dB}$. Therefore nurses should be alert to perturbing sounds such as alarms from infusion pumps, phone ringing, and the sound of nurse's shoes, in order to reduce disturbance levels and improve quality of care [68, 70-73].

\section{Temperature Levels Regulation}

Although the circadian clock can be entrained by temperature cycles [74], its free-running period is relatively constant within a broad range of physiological parameters. This phenomenon is called temperature compensation [75]. Extreme temperatures, however, have the potential to disrupt sleep continuity, and therefore may contribute to an adverse care environment. The threshold of recommended room temperature for healthy sleep is less than 75 degrees Fahrenheit $\left({ }^{\circ} \mathrm{F}\right)$. Thus, an adverse environment with extreme temperatures associated with changes in the level of light (e.g., combination of bright light/low temperature, darkness/hot temperature) may contribute to the disruption of continuous sleep. Nursing interventions should focus on maintaining the temperature of the hospital rooms at less than $75^{\circ} \mathrm{F}$ in order to improve sleep efficiency $[68,76]$.

\section{Adequate Drug Administration}

Suitable drug administration is important to align therapy to endogenous rhythms. Chronopharmacology refers the "design and evaluation of drug delivery systems that release a bioactive agent at a rhythm that ideally matches the biological requirement of a given disease therapy" [77]. The pharmacodynamics and pharmacokinetics of a drug can be altered according to the time of day that the medication is administered [78], thus controlling the efficacy and toxicity of the drug. Chronotherapy can be delivered through a variety of strategies and may include both time and sitespecific drug application regimens. Chronopharmacological techniques ensure that drug levels in the blood are within therapeutic ranges during periods of maximal disease severity. An example of this is seen in how evening doses of antihypertensive therapy can be used to prevent morning rises in blood pressure [79]. The evening dose of the drug may thus be well timed with diurnal changes in blood pressure, preventing diurnal worsening of hypertension. Another example is chemotherapy in which researchers have found that the toxic effects of more than 30 anticancer drugs vary by timing of administration [80].

Currently, however, a large number of drugs are administered without considering time of day or adjusting schedules to chronotherapeutic principles. This situation may lead to treatment failure or increased risk for drug toxicity. Furthermore, alterations in the circadian rhythms of biochemical, physiological, and behavioral processes induced by the drug itself can alter homeostatic regulation and exacerbate the disease [81-86]. Therefore, nurses must consider chronopharmacology as a means of increasing the efficacy of drugs and improving drug tolerance, paying attention to potential side effects of circadian disruption.

\section{Rationale for Management of Practices and Procedures}

Clinical procedures and tests in hospitalized patients often require patient preparation (food deprivation, fluid intake, laxatives, etc.), which induces stress and discomfort. Also, several usual care practices (such as taking vital signs or laboratory samples) are performed unexpectedly, without preparing the patient. Similarly, medium and high complexity surgical procedures are often programmed considering hospital's staff schedules and availability, regardless of a patient's biological chronotype. For example, vaginal delivery or caesarean sections are programmed in accordance to personnel convenience, thus altering the timing of the natural birth process.

Cognitive ability and capacity of the professionals who perform procedures may also vary throughout the day, which in turn may interfere with the procedure's duration and outcome. All these elements generate distress, anxiety, fear and further a patient's internal desynchronization. Additionally, it should be emphasized that several biochemical and physiological variables show a circadian variation [87-92].

\section{Control of Feeding Schedules}

There is an association between sleep duration and food intake [93]. The timing of food intake and behavior are controlled by the internal circadian clock, and the circadian control of food intake and digestion has important metabolic implications [93, 94]. For example, chronic circadian misalignment has been proposed to be the underlying cause for the adverse metabolic and cardiovascular health effects of shiftwork [95]. Furthermore, it was recently reported that timing of food intake influences the success of a weight-loss diet [96], suggesting that novel therapeutic strategies should incorporate not only the classic caloric intake and macronutrient distribution but also the timing of food. Thus "chrononutrition", appropriate times of food intake can prevent metabolic and circadian alterations in the patient, by reducing cardiovascular risks and improving nutrients' supply that collaborate to the patient's recovery [97-101]. 


\section{Encourage Social Interaction}

A disruption in social rhythms may lead to instability in circadian rhythms [102, 103]. The hospitalization process leads to a rupture of social ties, including separation from family, friends and daily activities [104]. Therefore, it is important that hospital nurses encourage social habits and interactions by facilitating visiting hours, providing information about what is happening in their environment, and promoting leisure and recreation. Better communication and interaction among patient, nurses and doctors regarding patient's health status will promote recovery. Taken together, these factors allow patients a proper synchronization with the social environment, reduce stress levels, and transition back into the family setting after hospital discharge.

\section{Promote Adequate Sleep Pattern (Sleep Hygiene)}

Disturbed sleep quality is associated with deficits in psychologic, behavioral, and somatic functions and predicts the emergence of deficits in interpersonal and psychosocial functioning [105]. Models used in the investigation of sleep quality emphasize the role of caretakers in ensuring that patients have a regular sleep/wake schedule, a suitable sleep environment, and a bedtime routine that prepares them physiologically, behaviorally, and emotionally for sleep. These practices, commonly referred to as sleep hygiene, influence sleep quality. Nurses will understand that, in addition to controlled environmental factors, there are a number of individual and intrinsic factors that induce and maintain sleep through personal routines [106].

In summary, there is clearly a need for incorporating these eight principles into bedside practice protocols as well as a need for further research to assess the positive outcomes of these efforts.

\section{THE THEORY AS A WHOLE}

There is strong scientific evidence that demonstrates a reciprocal relationship between a robust endogenous circadian system and the presence of regularly programed Zeitgebers. During disease, the correct function of the circadian synchronization system can be more dependent on exposure to intentionally programmed stimuli. Light levels, physical activity, temperature, and feeding are key elements for the internal synchronization of the central circadian clock and peripheral circadian oscillators. In such conditions, a regularly programed exposure to Zeitgebers, based on rational and scientific criteria, would be very important to recovery and well being [107]. Avoiding desynchronization and promoting circadian homeostasis contributes to optimal physiological function, general good health, and reduced susceptibility to comorbidities in persons with an acute or chronic illness [108]. For the health system, paying attention to circadian principles could reduce costs by preventive interventions that diminish patient complications and reduce hospital stay (Fig. 2).

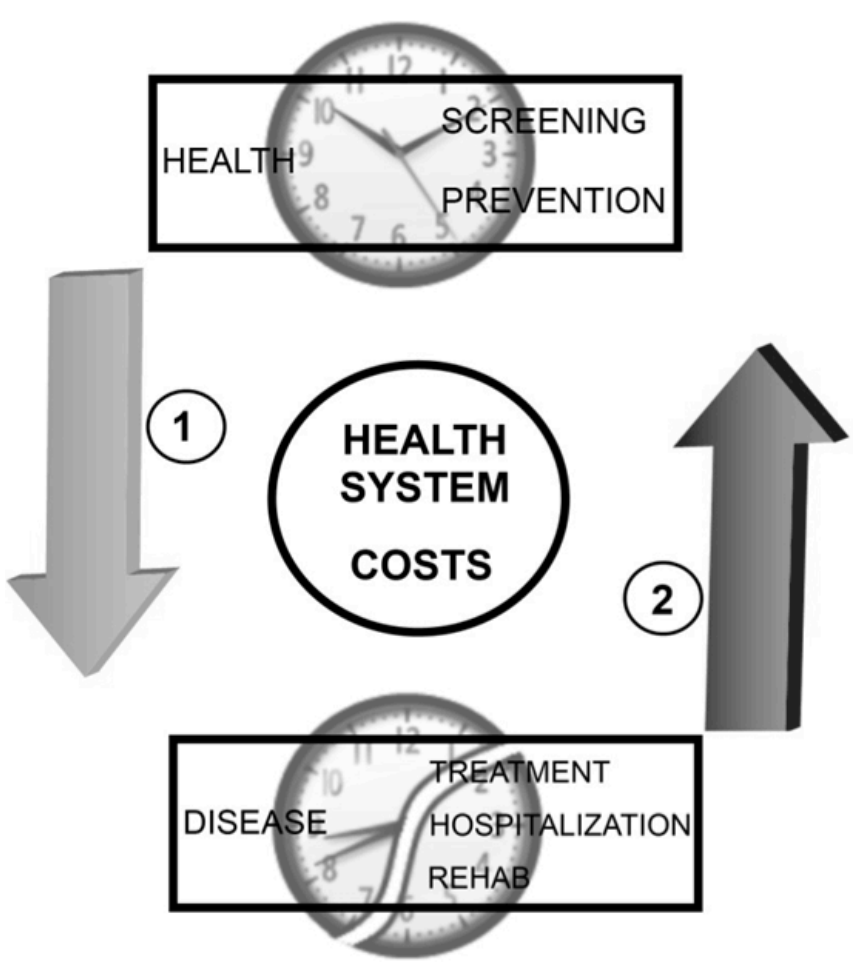

Fig. (2). The circadian nursing care of the hospitalized patient and costs in health system. A scientific nursing practice that makes the accurate intervention to correct the disruption of the patient's biological rhythms can reduce costs by avoiding prolonged hospitalary stays and severe complications in the patient (1). An inappropriate attention of the patient without considering biological rhythm's synchronizing and desynchronizing factors implies the probability of raising costs in the attention of health services and inappropriate quality of attention (2).

\section{CONCLUSION AND IMPLICATIONS FOR PRACTICE AND RESEARCH}

Chronobiology applied to patient care has broad implications for clinical practice, basic clinical research, and the training of new health care professionals. Knowledge of human circadian variations (physiological, psychological, behavioral, and social), as well as knowledge of how a disease behaves during a 24-hour period, considering its signs and symptoms, as well as the desired and undesired side effects of medications, will generate an appropriate care plan for the timing needs of the patient. A care plan should includes ensuring a stable external environment for the individual, with suitable light-dark cycles, low noise, constant temperature, and proper drug and food administration. In addition minimizing isolation and encouraging social interaction should be introduced into the plan of care for any long-term patient. This holistic approach presents an integration of existing scientific knowledge on chronobiology and the art and skill of nursing practice.

The patient is in continuous interaction with the environment (family, group, community, society, and 
hospital room) and, accordingly, experiences particular life styles and responses to health and disease. The need to have an updated knowledge base on biological rhythms requires that the nurse interact with other disciplines, both basic biomedical sciences and clinicians. Given that certain circadian traits are inherited, understanding the genetic architecture of molecular mechanisms of the circadian clock regulation can provide the necessary knowledge for individualizing patient care, and thus facilitating a rational therapeutic approach to their hospital care.

Finally, the performance of nursing care based on current scientific knowledge of chronobiology can positively impact the costs of health systems to detect and prevent elements of the individual or the environment that may disrupt or interfere with the patient's recovery. This can help reduce hospitalization time, medical and surgical complications, and reduce morbidity and mortality. However, more research is required in the area of circadian nursing care to determine the practical utility of this theory and to generate new knowledge that can strengthen the training of new professionals and the quality of current professional nursing practice.

\section{CONFLICT OF INTEREST}

The authors confirm that this article content has no conflict of interest.

\section{ACKNOWLEDGEMENTS}

The middle-range theory development was supported by grants from Universidad de Ciencias Aplicadas y Ambientales (U.D.C.A).

\section{REFERENCES}

[1] Aschoff J. Exogenous and endogenous components in circadian rhythms. Cold Spring Harb Symp Quant Biol 1960; 25: 11-28.

[2] Buonomano DV. The biology of time across different scales. Nat Chem Biol 2007; 3: 594-7.

[3] Feng D, Lazar MA. Clocks, metabolism, and the epigenome. Mol Cell 2012; 47: 158-67.

[4] Cornelissen G, Halberg F, Halberg J, Schwartzkopff O, Cugini P. Remembering the father of chronobiology and chronomics: Franz Halberg, MD (5 july 1919 - 9 june 2013). Clin Ter 2013; 164: I-VI.

[5] Golombek DA. Sleep is rhythm (and the rhythm, rhythm is). Vertex 2007; 18: 283-7.

[6] Schulz P, Steimer T. Neurobiology of circadian systems. CNS Drugs 2009; 23: 3-13.

[7] Ajay JY, Gajula PK, Kalaimagaland K, Hari BN. Chronopharmacognosy. Pharmacogn Rev 2012; 6: 6-15.

[8] Bass J. Circadian topology of metabolism. Nature 2012; 491: 34856.

[9] Halmos T, Suba I. Physiological and pathophysiological role of the circadian clock system. Orv Hetil 2012; 153: 1370-9.

[10] Savvidis C, Koutsilieris M. Circadian rhythm disruption in cancer biology. Mol Med 2012; 6: 1249-60.

[11] Slat E, Freeman GM Jr, Herzog ED. The clock in the brain: neurons, glia, and networks in daily rhythms. Handb Exp Pharmacol 2013; 217: 105-23.

[12] Dallmann R, Viola AU, Tarokh L, Cajochen C, Brown SA. The human circadian metabolome. Proc Natl Acad Sci USA 2012; 1409: $2625-9$

[13] Richards J, Gumz ML. Advances in understanding the peripheral circadian clocks. FASEB J 2012; 26: 3602-13.

[14] Tamosiunas G, Toledo M. Chronopharmacology: a new variable that could account for the variability of the therapeutic response. Arch Med Int 2010; 3: 65-9.
[15] Gómez-Sanz CA. Quality of sleep in patients hospitalized in an Intensive Care Unit. Enferm Intensiva 2012; 24: 3-11.

[16] Venkateshiah SB, Collop NA. Sleep and sleep disorders in the hospital. Chest 2010; 141: 1337-45.

[17] Dobratz MC. Toward development of a middle-range theory of psychological adaptation in death and dying. Nurs Sci Q 2011; 24: 370-6.

[18] Davidson JE. Facilitated sensemaking: a strategy and new middlerange theory to support families of intensive care unit patients. Crit Care Nurse 2010; 30: 28-39.

[19] Lee LY, Tsang AY, Wong KF, Lee JK. Using the Roy adaptation model to develop an antenatal assessment instrument. Nurs Sci Q 2011; 24: 363-9.

[20] Roy C. Research based on the Roy adaptation model: last 25 years. Nurs Sci Q 2011; 24: 312-20.

[21] McEachron DL. Timing is everything: a chronobiologist's perspective on health, illness, and circadian rhythms. Interview by Gloria F. Donnelly. Holist Nurs Pract 2012; 26: 188-93.

[22] Reimer AP, Moore SM. Flight nursing expertise: towards a middlerange theory. J Adv Nurs 2010; 66: 1183-92.

[23] Cagnacci A, Soldani R, Melis GB, Volpe A. Diurnal rhythms of labor and delivery in women: modulation by parity and seasons. Am J Obstet Gynecol 1998; 178: 140-5.

[24] Mancuso PJ, Alexander JM, McIntire DD, Davis E, Burke G, Leveno KJ. Timing of birth after spontaneous onset of labor. Obstet Gynecol 2004; 103: 653-7.

[25] Roizen J, Luedke CE, Herzog ED, Muglia LJ. Oxytocin in the circadian timing of birth. PLoS One 2007; 2: e922.

[26] Serón-Ferré M, Valenzuela GJ, Torres-Farfan C. Circadian clocks during embryonic and fetal development. Birth Defects Res C Embryo Today 2007; 81: 204-14.

[27] Akiyama S, Ohta H, Watanabe S, et al. The uterus sustains stable biological clock during pregnancy. Tohoku J Exp Med 2010; 221 287-98.

[28] Olcese J. Circadian aspects of mammalian parturition: a review. Mol Cell Endocrinol 2012; 349: 62-7.

[29] Brooks E, Canal MM. Development of circadian rhythms: role of postnatal light environment. Neurosci Biobehav Rev 2013; 37: 551-60.

[30] Iwata O, Okamura H, Saitsu H, et al. Diurnal cortisol changes in newborn infants suggesting entrainment of peripheral circadian clock in utero and at birth. J Clin Endocrinol Metab 2013; 98: E2532.

[31] Henderson JM, France KG, Owens JL, Blampied NM. Sleeping through the night: the consolidation of self-regulated sleep across the first year of life. Pediatrics 2010; 126: e1081-7.

[32] Kohyama J. Sleep as a window on the developing brain. Curr Probl Pediatr 1998; 28: 69-92.

[33] Adan A, Archer SN, Hidalgo MP, Di Milia L, Natale V, Randler C. Circadian typology: a comprehensive review. Chronobiol Int 2012; 29: $1153-75$

[34] Horne JA, Ostberg O. A self-assessment questionnaire to determine morningness-eveningness in human circadian rhythms. Int J Chronobiol 1976; 4: 97-110.

[35] Randler C. Age and gender differences in morningnesseveningness during adolescence. J Genet Psychol 2011; 172: 302-8 Collado-Mateo MJ, Díaz-Morales JF, Escribano-Barreno C, Delgado-Prieto P, Randler C. Morningness-eveningness and sleep habits among adolescents: age and gender differences. Psicothema 2012; 24: 410-5.

[37] Hagenauer MH, Lee TM. The neuroendocrine control of the circadian system: Adolescent chronotype. Front Neuroendocrinol 2012; 433: 211-229.

[38] Duffy JF, Dijk DJ, Klerman EB, Czeisler CA. Later endogenous circadian temperature nadir relative to an earlier wake time in older people. Am J Physiol 1998; 275: R1478-87.

[39] Vollmer C, Randler C, Di Milia L. Further evidence for the influence of photoperiod at birth on chronotype in a sample of German adolescents. Chronobiol Int 2012; 29: 1345-51.

[40] Waterhouse J, Fukuda Y, Morita T. Daily rhythms of the sleepwake cycle. J Physiol Anthropol 2012; 31: 5.

[41] Ridker PM, Willich SN, Muller JE, Hennekens CH. Aspirin, platelet aggregation, and the circadian variation of acute thrombotic events. Chronobiol Int 1991; 8: 327-35.

[42] Saitoh T, Watanabe Y, Kubo Y, et al. Intragastric acidity and circadian rhythm. Biomed Pharmacother 2001; 55: 138s-41s. 
[43] Azorin J, Kaladjian A. Depression and circadian rhythm. Encephale 2009; 35: S68-71.

[44] Shaw E, Tofler GH. Circadian rhythm and cardiovascular disease. Curr Atheroscler Rep 2009; 11: 289-95.

[45] Milhiet V, Etain B, Boudebesse C, Bellivier F. Circadian biomarkers, circadian genes and bipolar disorders. J Physiol Paris 2011; 105: 183-9.

[46] Besedovsky L, Lange T, Born JP. Sleep and immune function. Pflugers Arch 2012; 463: 121-37.

[47] Cutolo M. Chronobiology and the treatment of rheumatoid arthritis. Curr Opin Rheumatol 2012; 24: 312-8.

[48] Gonzalez Rodriguez E, Hernandez A, Dibner C, Ballan KB, Pechère-Bertschi A. Arterial blood pressure circadian rhythm: significance and clinical implications. Rev Med Suisse 2012; 8: 1709-12, 1714-5.

[49] Volicer L, Harper DG, Stopa EG. Severe impairment of circadian rhythm in Alzheimer's disease. J Nutr Health Aging 2012; 16: 88890.

[50] Wijnbergen I, Van't Veer M, Pijls NH, Tijssen J. Circadian and weekly variation and the influence of environmental variables in acute myocardial infarction. Neth Heart J 2012; 20: 354-9.

[51] Karatsoreos IN. Links between Circadian Rhythms and Psychiatric Disease. Front Behav Neurosci 2014; 8: 162.

[52] Buijs R, Kreier F. The metabolic syndrome: a brain disease? J Neuroendocrinol 2006; 18, 715-6.

[53] Kalsbeek A1, Palm IF, La Fleur SE, et al. SCN outputs and the hypothalamic balance of life. J Biol Rhythms 2006; 21: 458-69.

[54] Touitou Y. Internal clock desynchronization, light and melatonin. Bull Acad Natl Med 2011; 195: 1527-46, discussion 1547-9.

[55] Golombek DA, Casiraghi LP, Agostino PV, et al. The times they're a-changing: effects of circadian desynchronization on physiology and disease. J Physiol Paris 2013; 107: 310-22.

[56] Golombek DA, Bussi IL, Agostino PV. Minutes, days and years: molecular interactions among different scales of biological timing. Philos Trans R Soc Lond B Biol Sci 2014; 369: 20120465.

[57] Reinberg A, Ashkenazi I. Internal desynchronization of circadian rhythms and tolerance to shift work. Chronobiol Int 2008; 25: 62543.

[58] Lopes FM. Environment as a dimension in nursing metaparadigm. Servir 2008; 56: 189-99.

[59] Monk TH. Enhancing circadian zeitgebers. Sleep 2010; 33: 421-2.

[60] Kolla BP, Auger RR. Jet lag and shift work sleep disorders: how to help reset the internal clock. Cleve Clin J Med 2011; 78: 675-84.

[61] Pongratz G, Straub RH. Rheumatism, jet lag and the body clock. Z Rheumatol 2011; 70: 305-12.

[62] Sack RL. The pathophysiology of jet lag. Travel Travel Med Infect Dis 2009; 7: 102-10.

[63] Czeisler CA. Medical and genetic differences in the adverse impact of sleep loss on performance: ethical considerations for the medical profession. Trans Am Clin Climatol Assoc 2009; 120: 249-85.

[64] Ortiz-Tudela E, Bonmatí-Carrión Mde L, De la Fuente M, Mendiola P. Chronodisruption and ageing. Rev Esp Geriatr Gerontol 2012; 47: 168-73.

[65] Chepesiuk R. Extrañando la oscuridad: los efectos de la contaminación lumínica sobre la salud. Salud pública Méx 2010; 525: 47-7.

[66] Wakamura T, Tokura $\mathrm{H}$. Influence of bright light during daytime on sleep parameters in hospitalized elderly patients. J Physiol Anthropol Appl Hum Sci 2001; 20: 345-51.

[67] Czeisler CA. The effect of light on the human circadian pacemaker. Ciba Found Symp 1995; 183: 254-90; discussion 290-302.

[68] Linder LA, Christian BJ. Characteristics of the nighttime hospital bedside care environment (sound, light, and temperature) for children with cancer. Cancer Nurs 2011; 34: 176-84.

[69] West KE, Jablonski MR, Warfield B, et al. Blue light from lightemitting diodes elicits a dose-dependent suppression of melatonin in humans. J Appl Physiol (1985) 2011; 110: 619-26.

[70] Lei Z, Qiongjing Y, Qiuli W, Sabrina K, Xiaojing L, Changli W. Sleep quality and sleep disturbing factors of inpatients in a Chinese general hospital. J Clin Nurs 2009; 18: 2521-9.

[71] Buxton OM, Ellenbogen JM, Wang W, et al. Sleep disruption due to hospital noises: a prospective evaluation. Ann Intern Med 2012; 157: 170-9.

[72] Cordova AC, Logishetty K, Fauerbach J, Price LA, Gibson BR, Milner SM. Noise levels in a burn intensive care unit. Burns 2013; 39: 44-8.
[73] Hume KI, Brink M, Basner M. Effects of environmental noise on sleep. Noise Health 2012; 14: 297-302.

[74] Bodenstein C, Heiland I, Schuster S. Temperature compensation and entrainment in circadian rhythms. Phys Biol 2012; 9: 036011.

[75] Pittendrigh CS. On temperature independence in the clock system controlling emergence time in Drosophila. Proc Natl Acad Sci USA 1954; 40: 1018-29.

[76] Linder LA, Christian BJ. Nighttime sleep characteristics of hospitalized school-age children with cancer. J Spec Pediatr Nurs 2013; 18:13-24.

[77] Youan BB. Chronopharmaceutics: gimmick or clinically relevant approach to drug delivery? J Control Release 2004; 98: 337-53.

[78] Bruguerolle B, Boulamery A, Simon N. Biological rhythms: a neglected factor of variability in pharmacokinetic studies. J Pharm Sci 2008; 97: 1099-108.

[79] Acelajado MC, Pisoni R, Dudenbostel T, Oparil S, Calhoun DA, Glasser SP. Both morning and evening dosing of nebivolol reduces trough mean blood pressure surge in hypertensive patients. J Am Soc Hypertens 2012; 6: 66-72.

[80] Innominato PF, Lévi FA, Bjarnason GA. Chronotherapy and the molecular clock: Clinical implications in oncology. Adv Drug Deliv Rev 2010; 62: 979-1001.

[81] Ohdo S. Biological clock and chronopharmacology. Nihon Shinkei Seishin Yakurigaku Zasshi 2007; 27: 95-102.

[82] Bruguerolle B. Clinical chronopharmacology in the elderly. Chronobiol Int 2008; 25: 1-15.

[83] Lemmer B. Chronopharmacology--importance of the biological clock in drug treatment. Med Monatsschr Pharm 2009; 32: 419-25.

[84] Ohdo S. Chronopharmaceutics: pharmaceutics focused on biological rhythm. Biol Pharm Bull 2010; 33: 159-67.

[85] Ohdo S. Chronotherapeutic strategy: Rhythm monitoring, manipulation and disruption. Adv Drug Deliv Rev 2010; 62: 85975.

[86] Ando H, Fujimura A. Drug chronotherapy: the coordination of biological rhythms with medical treatment. Nihon Rinsho 2012; 70: 1222-6.

[87] Hillson SD, Rich EC, Dowd B, Luxenberg MG. Call nights and patients care: effects on inpatients at one teaching hospital. J Gen Intern Med 1992; 7:405-10.

[88] Baxendale S, Clancy J, McVicar A. Clinical implications of circadian rhythmicity for nurses and patients. Br J Nurs 1997; 6 , 303-9.

[89] Bailon RM, Cook CB, Hovan MJ, et al. Temporal and geographic patterns of hypoglycemia among hospitalized patients with diabetes mellitus. J Diabetes Sci Technol 2009; 3: 261-8

[90] Fernández JR, Hermida RC, Mojón A. Chronobiological analysis techniques. Application to blood pressure. Philos Trans A Math Phys Eng Sci 2009; 367: 431-45.

[91] Aperis G, Prakash P, Paliouras C, Papakonstantinou N, Alivanis P The role of melatonin in patients with chronic kidney disease undergoing haemodialysis. J Ren Care 2012; 38: 86-92.

[92] Chong MS, Tan KT, Tay L, Wong YM, Ancoli-Israel S. Bright light therapy as part of a multicomponent management program improves sleep and functional outcomes in delirious older hospitalized adults. Clin Interv Aging 2013; 8: 565-72.

[93] Grandner MA, Jackson N, Gerstner JR, Knutson KL. Dietary nutrients associated with short and long sleep duration: data from a nationally representative sample. Appetite 2013; 64: 71-80.

[94] Oike H, Oishi K, Kobori M. Nutrients, clock genes, and chrononutrition. Curr Nutr Rep 2014; 3: 204-212.

[95] Scheer FA1, Hilton MF, Mantzoros CS, Shea SA. Adverse metabolic and cardiovascular consequences of circadian misalignment. Proc Natl Acad Sci USA 2009; 106: 4453-8.

[96] Garaulet M, Gómez-Abellán P, Alburquerque-Béjar JJ, Lee YC, Ordovás JM, Scheer FA. Timing of food intake predicts weight loss effectiveness. Int J Obes (Lond) 2013; 37: 604-11.

[97] Leal AM, Moreira AC. Food and the circadian activity of the hypothalamic-pituitary-adrenal axis. Braz J Med Biol Res 1997; 30: 1391-405.

[98] Kasukawa T, Sugimoto M, Hida A, et al. Human blood metabolite timetable indicates internal body time. Proc Natl Acad Sci USA 2012; 109: 15036-41.

[99] Nakamura W. Circadian regulation of sleep-wake cycles and food anticipation. Brain Nerve 2012; 64: 647-56. 
[100] Sherman H, Genzer Y, Cohen R, Chapnik N, Madar Z, Froy O. Timed high-fat diet resets circadian metabolism and prevents obesity. FASEB J 2012; 26: 3493-502.

[101] Stenvers DJ, Jonkers CF, Fliers E, Bisschop PH, Kalsbeek A. Nutrition and the circadian timing system. Prog Brain Res 2012; 199: 359-76.

[102] Ehlers CL, Frank E, Kupfer DJ. Social zeitgebers and biological rhythms. A unified approach to understanding the etiology of depression. Arch Gen Psychiatry 1988; 45: 948-52.

[103] Castillo-Ruiz A, Paul MJ, Schwartz WJ. In search of a temporal niche: social interactions. Prog Brain Res 2012; 199: 267-80.
[104] Crnković M, Divcić B, Rotim Z, Corić J. Emotions and experiences of hospitalized school age patients. Acta Clin Croat 2009; 48: 12535 .

[105] Roberts RE, Roberts CR, Chen IG. Impact of insomnia on future functioning of adolescents. J Psychosom Res 2002; 53: 561-9.

[106] Meltzer LJ, Davis KF, Mindell JA Patient and parent sleep in a children's hospital. Pediatr Nurs 2012; 38: 64-71; quiz 72.

[107] Van Someren EJ, Riemersma-Van Der Lek RF. Live to the rhythm, slave to the rhythm. Sleep Med Rev 2007; 11: 465-84.

[108] Liu Z, Chu G. Chronobiology in mammalian health. Mol Biol Rep 2013; 40: 2491-501.

(C) Camargo-Sanchez et al.; Licensee Bentham Open.

This is an open access article licensed under the terms of the Creative Commons Attribution Non-Commercial License (http://creativecommons.org/licenses/by-nc/3.0/) which permits unrestricted, non-commercial use, distribution and reproduction in any medium, provided the work is properly cited. 